Special Article

\title{
THE ABUJA DECLARATION ON CELLS, TISSUE AND ORGAN DONATION AND TRANSPLANTATION
}

\author{
The participants of the Regional Consultation in the African Region on Cells, Tissue and \\ Organ Donation and Transplantation, Legal and Organisational Aspects, Abuja, Nigeria, \\ July 29-31, 2009.
}

The Istanbul Declaration initiated by The TransplantationSociety(TTS) and theInternational Society of Nephrology (ISN) exemplifies the commitment of professionals to work with health authorities at maintaining a high standard of ethics in the donation and transplantation of cells, tissues and organs. It is now endorsed by many national, regional and international scientific and professional bodies including the African Association of Nephrologists (AFRAN) and by the health authorities or national donation and transplantation agencies of many countries.

Under the auspices of the World Health Organisation (WHO), organ transplant experts representing governments across the African Region met in Abuja, Nigeria from July 29-31, 2009. The meeting was declared open by the Representative of The Federal Minister of Health of Nigeria. The objectives were:

- To promote national responsibilities on the donation and transplantation of cells, tissues and organs;

- To review the legal frameworks and provide guidance for proposed legislation on donation and transplantation;

- To review the situation of transplantation issues in the African Region in a global context;
- To update participants on the World Health Organisation's activities on donation and transplantation;

- To examine existing legal frameworks and organisation of donation and transplantation in member states;

- To provide guidance for improved legal frameworks for donation and transplantation.

\section{Observations}

Cell, tissue and organ transplantation (CTO) activities are at various stages in African countries. The most practised transplantations in Africa are kidney and corneal.

Due to the increase of the prevalence of noncommunicable diseases, such as diabetes and hypertension, the need for renal replacement therapy is great and will keep increasing.

Renal transplantation is the most cost-effective method of renal replacement. While living related transplant programs are available in a few countries, deceased donors' transplant programs exist only in South Africa. 
There is no legal framework and regulatory body overseeing organ transplantation in most African countries. This could result in unethical practices such as commercialism, organ trafficking and transplant tourism.

In line with its constitution, WHO has developed and updated a compendium of guiding principles to promote national responsibilities for organ transplantation. These provide the basis for a legal framework, with a view to standardising organ donation with respect to quality, safety, transparency, ethics and morals.

The collaboration between African countries and other regions, as well as with international agencies for knowledge, skills and resource sharing is currently very limited.

\section{Resulting recommendations from the Abuja Group}

The Group realised the gain in efficacy that could be brought by an ongoing regional networking of representatives of health authorities in charge of transplantation within the African countries facing similar challenges.

It was therefore agreed to follow the example of the Council of Europe Group that has been very productive in bringing together policy-makers to make key decisions on issues related to organ donation and transplantation. This was also the case very recently in South American countries.

Under the coordination of WHO, the Group of African Health Authorities Representatives on Donation Transplantation, the Abuja Group, intends to work during the coming months as a network with defined expected outcomes. The Chairman and Vice-Chairman will coordinate and ensure progress of the agreed tasks. It is expected that WHO and health authorities will reconvene the group within the coming year.

\section{List of recommendations}

\section{A. For participants}

1. To expand renal replacement therapy (RRT) to include haemodialysis, as well as peritoneal dialysis and transplantation for end-stage renal disease (ESRD).

2. To develop the capacity to provide oversight, organisation and coordination of donation and transplantation activities, with special attention to start donations from deceased donors and protect the health and welfare of living donors.

3. To sensitise national authorities on the importance of establishing a legal framework (taking into account WHO guiding principles) before any transplantation act.

4. To sensitise and provide technical expertise to the national health authorities to establish national programs to promote preventive activities that can result in decreasing the incidence of end-stage organ failure and corneal blindness.

5. To contribute to transparency in donation and transplantation, including the generation of national transplantation activity data and comprehensive sustained patients' and live donors' registries.

6. To organise a national assessment of the current situation of cell, tissue and organ transplantation (CTO).

7. To report to the World Health Organisation on an annual basis regarding national data on CTO.

8. To organise on a regular basis (every two years for example) national training sessions and sensitisation meetings on CTO.

9. To sensitise, elaborate on legislation and provide technical expertise to the national authorities on setting up regional/subregional donation and transplantation 
The Abuja Declaration on Cells, Tissue and Organ Donation and Transplantation

services in order to make the best of scarce resources in skills and equipment by achieving a level of activity sufficient to enable progress.

10. To identify affordable sources of equipment (batch purchase) and disposables in particular for the practice of peritoneal dialysis, preferably produced within the region.

11. To encourage contact and the creation of a regional network of corneal transplantation centres.

\section{B. For WHO}

1. To coordinate a regional network on CTO.

2. To raise political awareness by bringing CTO issues to the regional committee meeting within the next two (2) years.

List of participants:

Professor Adewale AKINSOLA

ILE-IFE, Nigeria (Chairman)

Professor Alain ASSOUNGA

Durban, South Africa (Vice-Chairman)

Dr John Ndugu NGIGI

Nairobi, Kenya (Rapporteur)

Dr Gloria ASHUNTANTANG

Yaounde, Cameroon

Dr Abdulhamid Isa DUTSE

Kano, Nigeria

Dr Linda EZEKIEL

Dar-es-Salaam, Tanzania

Dr Chris OSA ISOKPUNWU

Abuja, Nigeria

Professor M. Lamine SOW

Dakar, Senegal

Dr Salima MAGUEMOUN

Alger, Algeria
Dr Kouadio Koffi MATHURIN

Abidjan, Ivory Coast

Professor Seth Oumah MC'LIGEYO

Nairobi, Kenya

Dr Charlotte OSAFO

Accra, Ghana

Dr Alkaya Baba TOURE

Bamako, Mali

Dr Alemu WONDIE

Addis Ababa, Ethiopia

Professor Adewale AKINSOLA

ILE-IFE, Nigeria

Professor Alain ASSOUNGA

Durban, South Africa

Professor Francis DELMONICO

(T'TS, Member of WHO

Expert Advisory Panel on Transplantation)

Boston, MA, USA

Professor Boucar DIOUF

Dakar, Senegal

Dr Peter DOYLE

Lancashire, UK

Dr Elmi MULLER

Cape Town, South Africa

Dr John Ndugu NGIGI

Nairobi, Kenya

Dr Eduard SEVENSTER

Pretoria, South Africa

Dr Yonas TILAHUN

Addis Ababa, Ethiopia

WHO

Dr Luc NOËL

Geneva, Switzerland

Ms Mar CARMONA

Geneva, Switzerland 